\title{
Designing Assessment into a Study Abroad Course
}

\author{
Cathy Santanello \\ Southern Illinois University Edwardsville
}

\section{Laura Wolff \\ Southern Illinois University Edwardsville}

\section{Introduction}

One faces several challenges when designing an education abroad program. These include engaging non-traditional majors in study abroad experiences; facilitating learning activities that directly align with the learning goals of the courses; assessing specific learning outcomes; and finding ways to close the circle after the study abroad programs so that the experience becomes part of a continuum of lifelong learning.

Those involved in study abroad at Southern Illinois University Edwardsville (SIUE) share these challenges, together with the reality that the vast majority of our students are unwilling or unable to engage in a semester or academic year study abroad program due to financial constraints and familyrelated issues. SIUE's curriculum has an interdisciplinary course requirement and for more than 30 years the university has developed and offered teamtaught courses that include faculty from at least two disciplines.

Given this institutional culture, an increased enrollment of larger numbers of students studying abroad and an increase in the number of faculty leading programs has been achieved through the creation of team-taught, interdisciplinary, international courses where the study abroad experience typically lasts from two to three weeks. Many of these courses have featured a strong service learning component. In 2001, SIUE administrators and faculty made a deliberate attempt to attract science faculty and science students to service learning and study abroad. SIUE formed an exchange relationship with Costa Rica's Ministry of the Environment and focused the project, now called the Rainforest Project, at the. Carara, located on the central Pacific coast, is in a transitional forest zone. It is rich in biodiversity, making it an extraordinary study abroad site.

A rainforest community such as this one offers a unique educational setting for learning in a variety of disciplinary perspectives and service learning options. Carara National Park is well suited for service learning. The Park's 
mission is to identify, protect and preserve the many species that inhabit the park, and to educate visitors, schoolchildren and the general public, all tasks in which SIUE faculty and students could assist. Students from the scientific disciplines at SIUE who historically had not opted to study abroad or study foreign languages, have been attracted to this project because they are able to develop and use their skills to meet community identified needs of the Park. The relationship between SIUE and Carara has already produced many notable benefits for SIUE, Carara and the surrounding Costa Rican environment and community. These include:

1. construction of a biological research station that houses course participants;

2. ongoing monitoring of, and fundraising for, local Costa Rican endangered species such as the Scarlet Macaw and Olive Ridley Sea Turtle;

3. educational efforts that include environmental exhibits for Carara's visitor's center and a web site for Carara, http://www.siue.edu/PROVOST/CararaWebsite/index.html;

4. presentations by members of the CararaPpark staff to classes at SIUE and Carara, and SIUE student presentations at local elementary and middle schools;

5. improvements to the Park's educational trails; and

6. development of a joint meteorological research project that includes the installation of a weather station at the Park.

Since 2001, we have offered sixteen sections of the interdisciplinary service learning course to SIUE students at Carara National Park. Approximately 150 students and 19 faculty will have been part of this interdisciplinary project by the end of Summer 2006. We have planned and revised this course in recent years to meet the interests of various interdisciplinary teams.

The principles of course design as outlined by Fink (2003) were used to evaluate critically and refine the course. Fink describes an integrated course as one that incorporates such elements as situational factors, learning goals, assessment activities, instructional strategies, and course evaluations. The key to this design is not only having these components in place, but also integrating each step so that optimal student learning can be achieved. We highlight some aspects of Fink's process that have been particularly helpful in our course. We will describe our approach in incorporating distinct elements of these phases into our study abroad course. We will also explain how we assessed the course through the eyes of the currently enrolled students and course alumni. 


\section{Situational Factors}

The nature of the teaching and learning situation and the general characteristics of both the professors and the students are examples of situational factors that need to be considered every time a course is taught. Since our course is offered as a general education elective, it attracts students from a variety of majors, ages, experiences, and interests. Professors from Biology, Economics, Anthropology, Spanish, Geography, History, Political Science, Sociology, and Dance have led the course. Because the course is interdisciplinary and teamtaught it is important for the various subjects to mesh so that the students see the relevance and interconnectedness of the issues pertaining to the rainforest. As in any team-taught course, the various professors' philosophies on teaching and learning should be addressed as the syllabus is constructed, and the learning styles of the students should be considered as well.

The effects of the physical elements of the learning environment for this course also need to be considered. The lack of "Smart" classrooms or even traditional classrooms determines the modes of instruction. Lessons are covered at the dining table of the living quarters, Carara's Visitor's Center, or on educational outings. The classroom is brought to life by the variety of the cultural and environmental settings. Whether potential enhancements or obstacles to learning, these factors need to be considered as learning activities are constructed.

\section{Learning G o Is}

Once the situational factors are reviewed, the learning goals should be established. Our primary focus in setting our learning goals is on the impact the course will have on the students after the course has ended. We want to create lifelong learners who demonstrate better knowledge about the complex issues facing tropical rainforest communities, and have the ability to be global thinkers after the course is completed. We set our learning goals with these clear goals in mind: Intentional course design directly addresses this challenge.

With a goal of developing a learner-centered approach in this course we turned to Fink's Taxonomy of Significant Learning (Fink, 2003) to plot our learning goals. Fink's principles include:

- Foundational knowledge (learning facts, principles, etc.)

- Application (problem solving, creative activities, decision making)

- Integration (making connections between people, ideas, topics) 
- Human Dimensions (learning about self and others)

- Caring (understanding feelings, values, etc.)

- Learning How to Learn (self-directed learning)

Ideally, we want students to experience aspects of each of these principles as a result of this course; however, some are more germane to the course than others.

The course teaching/learning activities encompass some of these principles: foundational knowledge (lecture/discussions via cases and articles on Costa Rican flora/fauna, history, intercultural dance, etc.); application (critically thinking about case studies, decision making about park projects); integration (social interactions with the faculty/students, park staff, Central Americans and observations of the culture, environment, etc.); human dimensions and caring (working with others on cases and park activities and journaling about experiences); learning how to learn (to learn independently).

\section{Feedback and Assessment of Student Learning}

How do you assess whether students are learning as a result of a study abroad course and not just experiencing a trip to a foreign country? Appropriate assessments that are embedded into the study abroad course will complement the learning goals of the program an provide course assessment data.

The traditional approach to grading used in conventional, content-centered courses is backward looking; it assesses whether students learned by administering tests. However, learner-centered courses lend themselves to educative (forwardlooking) assessment measures. These measures help to determine if students are ready for a future activity as a result of the course. For example, a student might be asked, "Due to your experience in Costa Rica, are you more aware of global situations and are you more willing to support rainforest causes as a result of this course?" Using educative assessment measures, students conduct a self-assessment and an evaluation of their work and experiences. The reflective component is an integral part of the course. Students are also engaged in activities that simulate real-world experiences. These activities should allow the students and faculty to engage in dialogues that invoke students' critical thinking skills.

We have utilized the following three types of assessment:

- Journals/Reflective essays: Journaling encourages students to reflect on their experiences as they are occurring and to look critically at their experience and their environment. Journaling assignments can also 
serve an assessment function by asking students to "describe what you have learned that you couldn't have learned in a campus-based course" or "to describe new experiences or observations you have had in Costa Rica." These assessments can also be used to improve programming: we have used information obtained from journals to develop learning activities for future courses.

- Group Instructional Feedback Technique: We have had an independent faculty assessor accompany us with the last two courses and perform a classroom assessment activity called Group Instructional Feedback Technique or GIFT (Angelo and Cross, 1993). At the mid-point of the course, the assessor organizes the GIFT focus groups. They are asked to assemble into groups of three and are directed to discuss questions such: "What was the peak experience of this trip in terms of your learning about the environment, group learning, and the culture?" "What could we do more of, or less of, to make these peak experiences more likely for the next group of students?" After they have discussed the questions in their small groups, they reassemble and articulate their responses as a whole group. The assessor provides a written record of their replies and adds his/her perceptions of the learning environment based on the observations. The same assessor has accompanied us on both course trips and this has been helpful in providing consistent feedback for course development. That is, suggestions that students made about improving student learning outcomes were incorporated into design of the next course and we were able to see if the next group valued those changes. GIFT has also provided valuable feedback about that has led to appropriate changes being made to the course before its end. Because it has been so useful, we are planning to make this a permanent feature of the courses.

- Alumni assessment surveys: Surveys are administered a few weeks after the completion of the course to obtain additional data for future courses and to understand the influence the course has had on the students once it is over. We ask them to rate their responses to comments in the categories of learning, required coursework, group interaction, course goals, and general items. In addition, we ask them, "As you reflect upon this course in the future, what do you think will come to mind as your greatest learning experience?" We have used this survey since 2003, which has given us cumulative data that we use to assess the impact of the course. 


\section{What We Have Learned}

Assessments such as journaling, the Group Instructional Feedback Technique and alumni surveys continue to provide information to improve future courses. These tools have allowed us to assess our course goals and to evaluate group interactions, coursework and other details related to learning outcomes. Results tell us that students have gained a greater appreciation for study abroad and the tropical rainforest, and they believe the course has a greater impact on them than a traditional course offered strictly in a classroom setting. We have also learned that some of their experiences could have been enriched, and certain aspects of the course were not as successful as others.

In future course offerings, we plan to introduce during a pre-session meeting a learning styles inventory such as VARK (Visual, Aural, Read/write, and Kinesthetic sensory modalities; Fleming and Mills, 1992). By helping students understand their own learning preferences and those of others in the group, we may help to prevent conflicts that sometimes occur when people are living and working together in confined quarters. VARK may serve as a reminder that group work can be challenging and that groups should focus on a common goal despite individual learning and leadership styles.

The interdisciplinary nature of the course, and the makeup of its faculty leaders, makes consistency in expectations and the evaluation of various types of student projects challenging. We will attempt to address this difficulty by developing rubrics and implementing some faculty development activities with a goal of creating a shared sense of expectations that can be effectively communicated to students. Additionally, we are developing rubrics for the evaluation of student journaling, in order to provide greater consistency in evaluation, and, more importantly to clarify the expectations we have for the students.

\section{References}

Allen, R. D. (1991). Rain Forest Epiphytes. In Critical Thinking Case Study Workbook: Inquiry into Life, (pp. 113-116). Dubuque, IA: Wm. C. Brown. Angelo, T. A., \& Cross, K. P. (1993). Classroom Assessment Techniques: A Handbook for College Teachers (2nd ed.). San Francisco, CA: Jossey-Bass.

Boinski, S. (1992). Monkeys with Inflated Sex Appeal. Natural History, July, 42-49.

Bloom, B. S. (1954). Taxonomy of Educational Objectives: Book 1.Cognitive Domain. New York, NY: Longman.

Fink, L. D. (2003). Creating Significant Learning Experiences: An Integrative Approach to Designing College Courses. San Francisco, CA: Jossey-Bass. 
Fleming N. D. \& Mills C. (1992). Not Another Inventory, Rather a Catalyst for Reflection. In: D. H. Wulff, J. D. Nyquist (Eds.). To Improve the Academy (11), (pp.137-155). Bolton, MA: Anker Publishing.

Gastreich, K. (2002). Si el Norte Fuerta el Sur: A Case of Squirrel Monkey Identities. Retrieved July 10, 2005, from the National Center for Case Study Teaching in Science. University at Buffalo,_State University of New York web site: http:ublib.buffalo.edu/libraries/projects/cases.

Harris, P. R. \& Moran, R. T. (1991). Characteristics of Culture. In: Managing Cultural Differences: Global Leadership Strategies for the 21st Century (3rd ed.). Oxford, UK: Butterworth-Heinemann.

Miner, H. (1956) Body Ritual Among the Nacirema. American Anthropologist (58): 503-507. http://ublib.buffalo.edu/libraries/projects/cases. National Center for Case Study Teaching in Science. University at Buffalo, State University of New York. Last accessed 20 February, 2006.

Seege, A. (1995) Music and Dance of South and Central America. The JVC/ Smithsonian Folkways Anthology of Music and Dance in the Americas: Central and South America, Multicultural Media, Montpelier, VT

www.cispes.org. (2004) Women Say No to Cafta. Intl Gender \& Trade Network. Last accessed 15 June, 2005.

Walvoord, B. \& Anderson, V. J. (1998) Effective Grading: A Tool for Learning and Assessment. San Francisco, CA: Jossey-Bass. 
